\title{
Effects of intermittent chemical dosing on volatile sulfur compounds in sewer headspace
}

\author{
Guijiao Zhang ${ }^{1,2}$, Tianfeng Gu' ${ }^{1}$, Yongchao Zhou ${ }^{{ }^{\dagger}}$, David Z. Zhu' ${ }^{2}$, Yiping Zhang ${ }^{1}$ \\ ${ }^{1}$ College of Civil Engineering and Architecture, Zhejiang University, Hangzhou, China \\ ${ }^{2}$ Department of Civil and Environmental Engineering, University of Alberta, Edmonton, Canada
}

\begin{abstract}
Volatile sulfur compounds (VSCs), including hydrogen sulfide $\left(\mathrm{H}_{2} \mathrm{~S}\right)$ and volatile organic sulfide compounds (VOSCs), can be produced in sewer systems causing sewer odor problems. In this study, the effects of intermittently dosing ferric iron, hydrogen peroxide, and nitrate on $\mathrm{H}_{2} \mathrm{~S}$ and VOSCs in sewer headspace were investigated. In order to characterize the composition of VSCs, an HC-3 trace sulfur analyzer and gas chromatograph (GC) equipped with a triple quadrupole-type mass spectrometry (MS) apparatus were used to determine the VSCs. The results indicated that the effect of intermittent addition of $40 \mathrm{mg} / \mathrm{L}$ ferric iron or $40 \mathrm{mg} / \mathrm{L}$ hydrogen peroxide is limited for VSCs inhibition. The $\mathrm{H}_{2} \mathrm{~S}$ and VOSCs concentrations increased significantly in the late-stage experiments, even around $20 \%$ and $30 \%$ respectively higher than the initial average concentrations. However, the intermittent addition of $40 \mathrm{mg} \mathrm{N} / \mathrm{L}$ nitrate has a relatively stable control effect of $\mathrm{H}_{2} \mathrm{~S}$ and VOSCs which maintaining $60 \%$ removal rate. Moreover, methyl mercaptan (MeSH) was the most abundant compound of the total VOSCs released and the results of the theoretical odor concentration study also indicate MeSH is the main VOSC causing the significant odor problem. Therefore, more attention should be focused on the VOSCs which have extremely low odor threshold.
\end{abstract}

Keywords: Chemical dosing; Headspace phase; Sewer odor; Theoretical odor concentration; Volatile sulfur compounds

\section{Introduction}

During the transport of sewage over a long distance, various odorous compounds can be produced in sewer systems cause sewer odor problems and adverse health effects [1]. Hydrogen sulfide $\left(\mathrm{H}_{2} \mathrm{~S}\right)$ is a volatile and poisonous compound with rotten egg smell which is considered the major reason for odor emission in sewer management. Sulfide also can cause the corrosion of sewer infrastructure and has a detrimental effect on human health. Various chemical dosing methods have been extensively used to remove $\mathrm{H}_{2} \mathrm{~S}$ in sewer networks [2].

The commonly used chemicals to mitigate the negative effects of sulfide are iron salts, oxygen, nitrate, sodium hydroxide, magnesium hydroxide [3]. All these chemicals, except for $\mathrm{NaOH}$, typically require continuous dosing strategy. However, continuous dosing will result in high chemical supply costs. Besides, the intermittent operation of pumping stations makes traditional continuous dosing inadequate. Therefore, the intermittent dosing strategy was proposed as an alternative cost-effective strategy for sulfide elimination, especially in the condition of periodical operation of pump stations. Liu et al. [4] proposed intermittent nitrate dosing for sulfide control in sewer sediments. Jiang et al. [5] investigated the intermittent dosing of free nitrous acid as a measure for controlling sulfide and methane production. Moreover, the sulfide compounds control effect of the intermittent dosing was also assessed in other previous researches [6].

On the other hand, VOSCs such as methyl mercaptan (MeSH), dimethyl sulfide (DMS), dimethyl disulfide (DMDS), dimethyl trisulfide (DMTS), carbon disulfide $\left(\mathrm{CS}_{2}\right)$, and ethanethiol (EtSH) with obnoxious odors also can be produced in sewers which can subsequently be transferred to the headspace air by mass transfer [7]. In terms of odor impact, VOSCs may still cause serious odor problems due to their extremely low odor threshold values. However, the bulk of investigations have focused entirely on the variation of sulfide in the liquid phase before and after treatment. The control effect of intermittent dosing on typical VOSCs (MeSH, EtSH, DMS, DMDS, and $\mathrm{CS}_{2}$ ) is unclear.

This study aims to understand the typical VOSCs and $\mathrm{H}_{2} \mathrm{~S}$ concen-
This is an Open Access article distributed under the terms of the Creative Commons Attribution Non-Commercial License (http://creativecommons.org/licenses/by-nc/3.0/) which permits unrestricted non-commercial use, distribution, and reproduction in any medium, provided the original work is properly cited.

Copyright (C) 2022 Korean Society of Environmental Engineers
Received February 15, 2021 Accepted April 23, 2021

${ }^{\dagger}$ Corresponding author

E-mail: zhoutang@zju.edu.cn

Tel: +86-0571-88206587 Fax: +86-0571-88206587

ORCID: 0000-0002-5524-4016 
tration variation in sewer headspace with intermittently chemical dosing such as ferric iron, hydrogen peroxide, and nitrate. Moreover, the odor control effect of three chemicals was evaluated by theoretical odor concentration. Besides, the changes in the composition of microbial communities in sewage after intermittent chemical dosing were explored through 16s rRNA gene sequencing over the period to discuss the control mechanism.

\section{Methods and Materials}

\subsection{Experimental Setup and Operation}

The system consists of three laboratory-scale PersPex ${ }^{\mathrm{TM}}$ reactors operated in parallel, namely R1, R2, and R3. Each reactor had a volume of $1.9 \mathrm{~L}$, with a diameter of $90 \mathrm{~mm}$ and a height of $300 \mathrm{~mm}$ and equipped with a gas sampling port as shown in Fig. 1. The sediment samples were collected using a cleaning device from the main sewer in Hangzhou, China, which were then transported to the lab and kept at $4^{\circ} \mathrm{C}$ before usage $[8,9]$. The sediment samples had the following properties: bulk density $1.22 \mathrm{~g} / \mathrm{cm}^{3}$; total solids (TS) $75.2 \%$; and volatile solids (VS) $4.8 \%$ [10]. $380 \mathrm{~mL}$ sediment was inoculated in each reactor, resulting in an initial sediment depth of $60 \mathrm{~mm}$. Synthetic domestic wastewater was used in this study according to the previous study [11]. Sulfate concentration was prepared with $66 \pm 3 \mathrm{mg} / \mathrm{L}$ and the chemical oxygen demand (COD) concentration was $300 \pm 10 \mathrm{mg} / \mathrm{L}$. The reactors were fed with synthetic wastewater through a peristaltic pump intermittently and the liquid and gas in each reactor were replaced completely every $24 \mathrm{~h}$.

The reactors had been operated anaerobically for $30 \mathrm{~d}$ at 25 $\pm 5^{\circ} \mathrm{C}$ before this study was conducted. This experiment was conducted

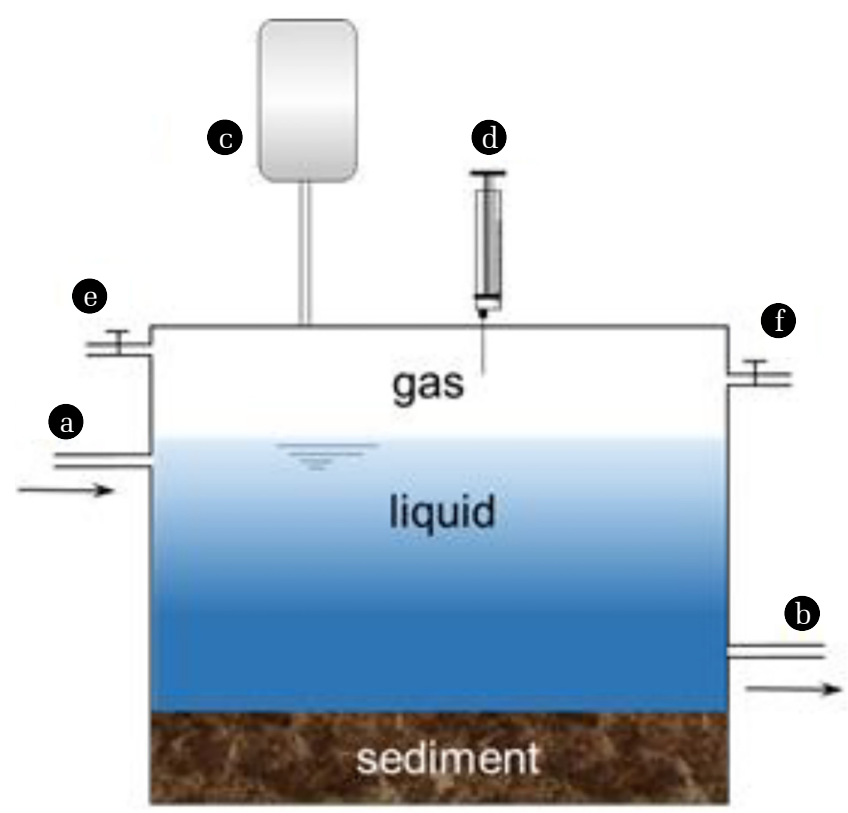

Fig. 1. Schematic diagram of the sewer sediment reactor. (a) water inlet, (b) water outlet, (c) the Teflon gas collecting bag, (d) gas sample, (e) gas inlet, (f) gas outlet. in two phases. In phase I, the monitoring was performed for 5 d (Day 1 to Day 5) before starting the chemical addition to confirm the steady-state conditions in terms of VSCs production. In phase II (Day 6 to Day 10), the R1, R2, and R3 were intermittently dosed with ferric, $\mathrm{H}_{2} \mathrm{O}_{2}$, and nitrate, respectively every $24 \mathrm{~h}$. These chemical agents have different mechanisms for VSCs elimination. Nitrate is a thermodynamically favorable electron acceptor, while $\mathrm{H}_{2} \mathrm{O}_{2}$ is a strong oxidant. Ferric ions $\left(\mathrm{Fe}^{3+}\right)$ oxidize sulfide to elemental sulfur while being reduced into $\mathrm{Fe}^{2+}$, which precipitates with sulfide to form ferrous sulfide precipitants.

Throughout the two phases, the gas samples in each reactor were collected each day at 9:00 $\mathrm{h}$ for analysis of the sulfur-containing compounds. After sampling, fresh synthetic sewage was pumped to the reactor to thoroughly replace the previous liquid in reactors. Then, the gas-phase in reactors was purged with high purity nitrogen gas (500 $\mathrm{mL} / \mathrm{min}$ ) for $20 \mathrm{~min}$ every day after sampling to remove previous gas remaining.

\subsection{Chemical Analysis Method}

The MeSH and $\mathrm{H}_{2} \mathrm{~S}$ concentrations were determined using an HC-3 trace sulfur analyzer and gas chromatograph (GC) equipped with a flame ionization detector (FID). The HC-3 trace sulfur analyzer equipped with a polytetrafluoroethylene column and a flame photometric detector was used for the analysis of $\mathrm{MeSH}$, with high-purity nitrogen $(10 \mathrm{~mL} / \mathrm{min})$ as the carrier gas. $\mathrm{H}_{2} \mathrm{~S}$ was detected by $\mathrm{GC}$ with FID equipped with a DB-624 capillary column $(30 \mathrm{~m} \times 0.320$ $\mathrm{mm} \times 1.80 \mu \mathrm{m})$. Nitrogen was chosen as the carrier gas, with a flow of $12 \mathrm{~mL} / \mathrm{min}$. The respective temperature of the chromatographic column, sample injector, and detector was set at $120^{\circ} \mathrm{C}$, $250^{\circ} \mathrm{C}$, and $220^{\circ} \mathrm{C}$ [12].

Other sulfur-containing gases such as EtSH, DMS, DMDS, and $\mathrm{CS}_{2}$ were identified by full-scan using a triple quadrupole-type mass spectrometry (MS) apparatus (Agilent 6890N GC and 5975B MS). The chromatographic column used was DB-624 $(60 \mathrm{~m}$ $\times 0.25 \mathrm{~mm} \times 1.40 \mu \mathrm{m}$ ) and the carrier gas flow was maintained at $1.0 \mathrm{~mL} / \mathrm{min}$ flow rate. The GC oven temperature program was as follows: initial $35^{\circ} \mathrm{C}$ was held for $3 \mathrm{~min}$, increasing at a rate of $6^{\circ} \mathrm{C} / \mathrm{min}$ to $140^{\circ} \mathrm{C}$, then at a rate of $10^{\circ} \mathrm{C} / \mathrm{min}$ to $220^{\circ} \mathrm{C}$, held for $3 \mathrm{~min}$. The temperature of the injector and detector was maintained at $140^{\circ} \mathrm{C}$ and $220^{\circ} \mathrm{C}$, respectively. Electron impact ionization (EI) was used as an ionization mode of the MS. Ion source temperature was kept at $230^{\circ} \mathrm{C}$. The selected ion monitoring (SIM) mode of EI was also applied in the quantitative analysis.

\subsection{Theoretical odor Concentration}

The odor threshold concentration of each volatile sulfur compound varies widely shown in Table S1 [13]. High volatile compound concentration does not always cause malodor. Therefore, the theoretical odor concentration (TOC) is used to identify the main odorous substances which are based on the ratio of odorous compound concentration and its odor threshold value, as shown in Eq. (1) and Eq. (2) [14].

$$
D_{i}=\frac{C_{i}}{C_{i}^{T}}
$$




$$
D_{T}=\sum_{i=1}^{n} D_{i}
$$

where $C_{i}$ is the analytical concentration of compound $i\left(\mu \mathrm{g} / \mathrm{m}^{3}\right)$; $C_{i}^{T}$ is the odor threshold concentration of compound $i\left(\mu \mathrm{g} / \mathrm{m}^{3}\right)$; $D_{i}$ is defined as "theoretical odor concentration"; $n$ is the total number of compounds; $D_{T}$ is the total theoretical odor concentration of all $n$ compounds.

\subsection{Microbial Community Analysis}

On Day 4, Day 6, and Day 10, the biofilm samples in wastewater were collected from each sewer reactor. The total genomic DNA was extracted from collected samples using the PowerMax ${ }^{\mathrm{TM}}$ DNA Kit according to manufacturer instructions (MOBIO Laboratories, San Diego, CA, USA) and quantified using the Nanodrop ND-1000 spectrophotometer (Thermo Fisher Scientific, Waltham, MA, USA). The extracted genomic DNA (gDNA) was amplified with the primers 515F/806R (515F:5'-GTGCCAGCMGCCGCGGTAA-3';806R:5'GGACTACVSGGGTATCTAAT-3') targeting the V4 hypervariable region [15]. The PCR was conducted for each sample of the reaction mixture $(50 \mu \mathrm{L})$ containing $25 \mu \mathrm{L}$ of Phusion High-Fidelity PCR Master Mix with HF Buffer, $3.0 \mu \mathrm{L}$ of each primer, $10 \mu \mathrm{L}$ of template DNA, and nuclease-free water. The PCR conditions were as follows: initial denaturing step at $98^{\circ} \mathrm{C}$ for $30 \mathrm{~s}$, followed by 25 cycles of $98^{\circ} \mathrm{C}$ for $15 \mathrm{~s}, 58^{\circ} \mathrm{C}$ for $15 \mathrm{~s}, 72^{\circ} \mathrm{C}$ for $60 \mathrm{~s}$, and a final extension of $10 \mathrm{~min}$ at $72^{\circ} \mathrm{C}$. Subsequently, PCR products of each sample were purified by AMPure XP beads (Beckman Coulter, Indianapolis, IN) and quantified using the PicoGreen dsDNA Assay Kit (Invitrogen, Carlsbad, CA, USA). A mixture of the amplicons was then used for high-throughput sequencing on the Illumina MiSeq platform [16].

After sequencing, the primers and spacers were trimmed. To minimize the effects of random sequencing error, both the low quality (lower than 20) and the sequences shorter than $150 \mathrm{bp}$ were removed. The operational taxonomic units (OTUs) analysis was used by Vsearch v2.4.4. The OTUs were picked by using the de novo OTUs picking protocol with a $97 \%$ identity threshold. The VENARCH was used to perform species annotation on the representative sequence based on the SILVA128 database and further generated OTU lists.

\section{Results and Discussion}

\subsection{Concentration Changes of VSCs in Headspace Gas Phase}

The odor of volatile pollutants that escaped from the sewers is primarily caused by VSCs (i.e., VOSCs and $\mathrm{H}_{2} \mathrm{~S}$ ) released from the liquid phase. Therefore, we evaluate the VSCs concentration variation in headspace $24 \mathrm{~h}$ after each dosing. The variation of total VSCs concentration, as well as VOSCs and $\mathrm{H}_{2} \mathrm{~S}$ percentage in the headspace before (Phase I) and after $\mathrm{FeCl}_{3}, \mathrm{H}_{2} \mathrm{O}_{2}$, and $\mathrm{KNO}_{3}$ intermittent dosing (Phase II) are shown in Fig. 2. In Phase I, the total VSCs concentration in the headspace ranged from 15,000 to $23,000 \mu \mathrm{g} / \mathrm{m}^{3}$. VOSCs had much higher concentrations than $\mathrm{H}_{2} \mathrm{~S}$ in Phase I, accounting for nearly $90 \%$ of total VSCs concentration. It might be attributed to the degradation of sulfur-containing amino acids such as methionine and cysteine in wastewater, which was usually decomposed to VOSCs by deamination and demethylation. The result in this study was constant with the previous study which showed VOSCs were the highest concentration of the detected VSCs [14]. In Phase II, the intermittent addition of $\mathrm{FeCl}_{3}, \mathrm{H}_{2} \mathrm{O}_{2}$, and $\mathrm{KNO}_{3}$ contributed to significant decreases in the VSCs concentrations in the first three days. The total VSCs in the headspace decreased from 22,000-24,500 $\mu \mathrm{g} / \mathrm{m}^{3}$ to $6,200-7,500 \mu \mathrm{g} / \mathrm{m}^{3}$ for ferric iron and nitrate intermittent addition, from $20,000 \mu \mathrm{g} / \mathrm{m}^{3}$ to $9,800 \mu \mathrm{g} / \mathrm{m}^{3}$ for $\mathrm{H}_{2} \mathrm{O}_{2}$ addition. However, the total VSCs concentration picked up in the last two days and reached around $25,000 \mu \mathrm{g} / \mathrm{m}^{3}$ for ferric iron and $\mathrm{H}_{2} \mathrm{O}_{2}$ addition, while it rebounded slowly and increased to 11,500 $\mu \mathrm{g} / \mathrm{m}^{3}$ for nitrate addition. In Phase II, VOSCs were still the most abundant, with an average percentage concentration of $80 \%, 82 \%$, and $86 \%$, respectively, while the proportion of $\mathrm{H}_{2} \mathrm{~S}$ increased slightly.

Fig. 3 displays the total VOSCs and $\mathrm{H}_{2} \mathrm{~S}$ concentration in the headspace in Phase I and II. The initial VOSCs concentrations in R1, R2, and R3 ranged from 14,700-22,000 $\mu \mathrm{g} / \mathrm{m}^{3}$, $15,200-19,900 \mu \mathrm{g} / \mathrm{m}^{3}$, and $13,400-24,600 \mu \mathrm{g} / \mathrm{m}^{3}$, respectively, which were much higher than the results of field studies [7, $16,17]$ probably because of the optimal lab condition of microorganisms growth and higher sulfur content. In Phase II, $\mathrm{FeCl}_{3}$, $\mathrm{H}_{2} \mathrm{O}_{2}$, and $\mathrm{KNO}_{3}$ addition caused a substantial decrease of VOSCs

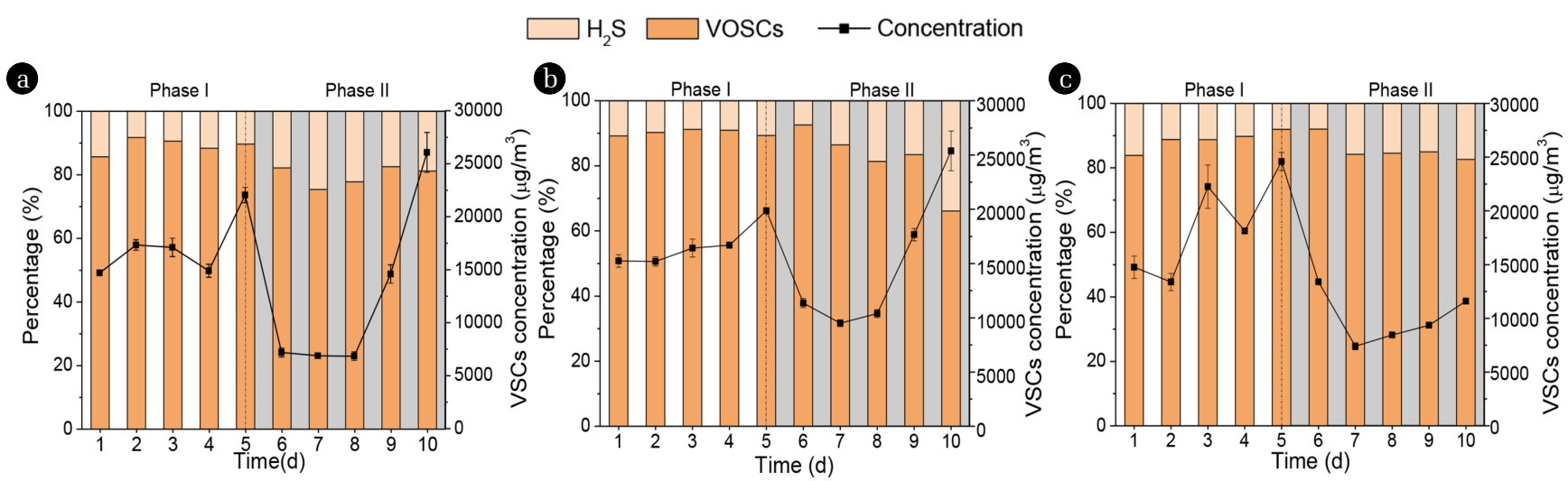

Fig. 2. Variation of total VSCs concentrations and the percentage of $\mathrm{H}_{2} \mathrm{~S}$ and VOSCs in the headspace in Phase I and II with the addition of (a) ferric iron, (b) hydrogen peroxide, (c) nitrate. 

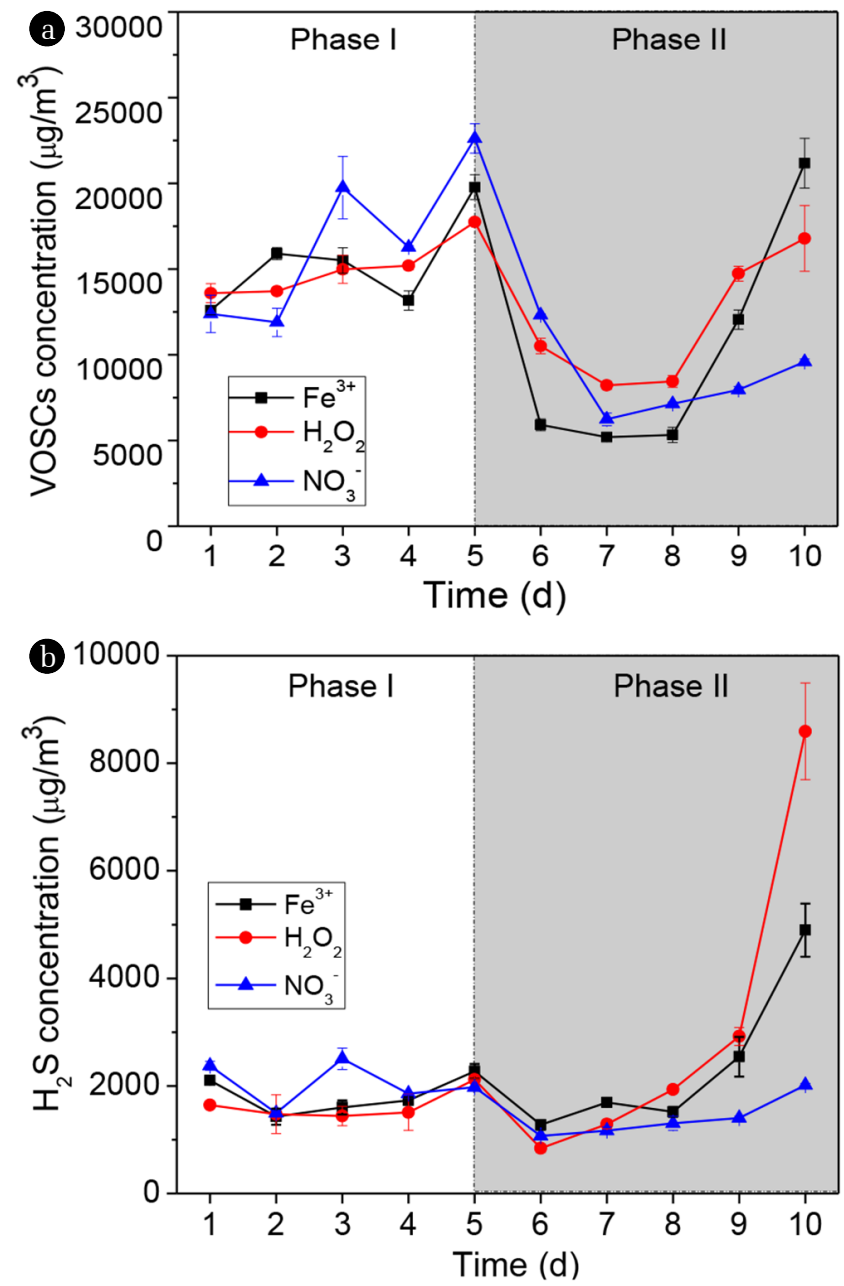

Fig. 3. Variation of the total VOSCs and $\mathrm{H}_{2} \mathrm{~S}$ concentrations in the headspace in Phase I and II (a) VOSCs; (b) $\mathrm{H}_{2} \mathrm{~S}$.

on day 6 to day 8 , reaching the average concentration of 5,300 $\mu \mathrm{g} / \mathrm{m}^{3}, 8,400 \mu \mathrm{g} / \mathrm{m}^{3}$, and $7,100 \mu \mathrm{g} / \mathrm{m}^{3}$, respectively. However, the VOSCs concentrations in the treatment of $\mathrm{FeCl}_{3}$ and $\mathrm{H}_{2} \mathrm{O}_{2}$ increased significantly on day 9 and day 10, even at the end of the experiment around $20 \%$ and $30 \%$, respectively higher than the initial average VOSCs concentrations. For $\mathrm{H}_{2} \mathrm{~S}$, its concentration also decreased from about $2,000 \mu \mathrm{g} / \mathrm{m}^{3}$ to about $1,000 \mu \mathrm{g} / \mathrm{m}^{3}$ on the first day of Phase II (Fig. 3(b)). Previous studies have shown that all three chemicals that possess oxidization could oxidize sulfide chemically. Besides, ferric iron could precipitate sulfide while nitrate could oxidize sulfide biologically by stimulating heterotrophic nitrate-reducing bacteria (hNRB) and nitrate-reducing sulfide-oxidizing bacteria (NR-SOB) in sediment. Therefore, a good sulfide control effect after treatment could be achieved. However, a similar rebound trend was also observed, and the $\mathrm{H}_{2} \mathrm{~S}$ increased four-fold and two-fold in the intermittent addition of $\mathrm{FeCl}_{3}$ and $\mathrm{H}_{2} \mathrm{O}_{2}$ respectively on the last day. $\mathrm{H}_{2} \mathrm{O}_{2}$ has been used to reduce COD and offensive odor in domestic or industrial wastewater for many years [18], but the disadvantage is the short lifetime of $\mathrm{H}_{2} \mathrm{O}_{2}$ [19]. Moreover, sulfide oxidation by $\mathrm{H}_{2} \mathrm{O}_{2}$ could also involve the formation of elemental sulfur [20]. Ferric ions also could oxidize sulfide to elemental sulfur while being reduced into ferrous ions [21]. The produced elemental sulfur accumulated on the sediment probably attributed to the rebound of VSCs in the later-stage of the experiment. Besides, different chemicals including ferric chloride and hydrogen peroxide showed that all could reduce VOSCs production in biosolids and freshwater sediment, and none were vastly superior to the other [22]. However, the result in this study showed that the concentration of VOSCs rebounded in the late-stage experiment which was inconsistent with the previous study. This result could attribute to the sewer sediment composition which needs further research. On the contrary, the $\mathrm{H}_{2} \mathrm{~S}$ and VOSCs concentrations are relatively stable after the addition of nitrate and increased slightly to $1,700 \mu \mathrm{g} / \mathrm{m}^{3}$ and $8,000 \mu \mathrm{g} / \mathrm{m}^{3}$, respectively. Previous studies revealed that syntrophic degradation of VOSCs by methanogens and nitrate-reducing bacteria could exist in freshwater sediments [23]. Therefore, nitrate addition could stimulate nitrate-reducing bacteria to thrive in the sewer sediment which could degrade VOSCs thereby maintain the VOSCs control efficacy. This result indicated that nitrate could be a preferred option among the intermittent dosage for VSCs control.

\subsection{Variation of VOSCs Concentrations in Sewer Headspace Air}

$\mathrm{MeSH}, \mathrm{EtSH}, \mathrm{DMS}, \mathrm{CS}_{2}$, and DMDS were detected in the headspace phase. The variation of total VOSCs and the proportions of five components in the headspace are shown in Fig. 4. MeSH was the most abundant compound in the total VOSCs, accounting for around 95\% of the VOSCs in Phase I and II. This result agreed with the previous reports that VOSCs were generally dominated by $\mathrm{MeSH}[7,16]$. In Phase II, the proportion of MeSH was reduced slightly by $12 \%, 20 \%$, and $5 \%$ on day 6 by the addition of $\mathrm{FeCl}_{3}, \mathrm{H}_{2} \mathrm{O}_{2}$, and $\mathrm{KNO}_{3}$, respectively. However, it was observed that the proportion of DMDS increased, especially with the treatment of $\mathrm{H}_{2} \mathrm{O}_{2}$. It is likely due to DMDS was formed by oxidation of MeSH [24]. The levels of EtSH, DMS, and $\mathrm{CS}_{2}$ were relatively low, constituting less than $3 \%$ of the initial total VOSCs, even changed little after chemical intermittent dosing.

Fig. 5 illustrated the concentration variation of each VOSCs (MeSH, EtSH, DMS, $\mathrm{CS}_{2}$, and DMDS) in the headspace during Phase I and Phase II. The initial concentration of MeSH fluctuated between 12,100-19,100 $\mu \mathrm{g} / \mathrm{m}^{3}, \quad 13,000-17,200 \mu \mathrm{g} / \mathrm{m}^{3}$ and $11,300-21,900 \mu \mathrm{g} / \mathrm{m}^{3}$, respectively in Phase I. In Phase II, the emission of $\mathrm{MeSH}$ was reduced by $74 \%, 54 \%$, and $50 \%$ by the addition of $\mathrm{FeCl}_{3}, \mathrm{H}_{2} \mathrm{O}_{2}$, and $\mathrm{KNO}_{3}$, respectively, on day 6. However, it was also observed that there was a marked increase of $\mathrm{MeSH}$ concentration in the treatment with $\mathrm{FeCl}_{3}$ and $\mathrm{H}_{2} \mathrm{O}_{2}$ on day 9, even jumped to $20,200 \mu \mathrm{g} / \mathrm{m}^{3}$ and $16,200 \mu \mathrm{g} / \mathrm{m}^{3}$, respectively on day 10. The DMDS concentration tended to increase after all three chemicals addition on day 6 , it even rose from around $280 \mu \mathrm{g} / \mathrm{m}^{3}$ to $2,400 \mu \mathrm{g} / \mathrm{m}^{3}$ with $\mathrm{H}_{2} \mathrm{O}_{2}$ treatment, but it then decreased sharply to around $500 \mu \mathrm{g} / \mathrm{m}^{3}$ on day 7 . The results indicate that a greater amount of DMDS can originate from the chemical oxidation of methyl mercaptan when dosing strong oxidants such as hydrogen peroxide [25, 26]. The other three VOSCs (EtSH, DMS, and $\mathrm{CS}_{2}$ ) showed no significant differences among the three chemical treat- 


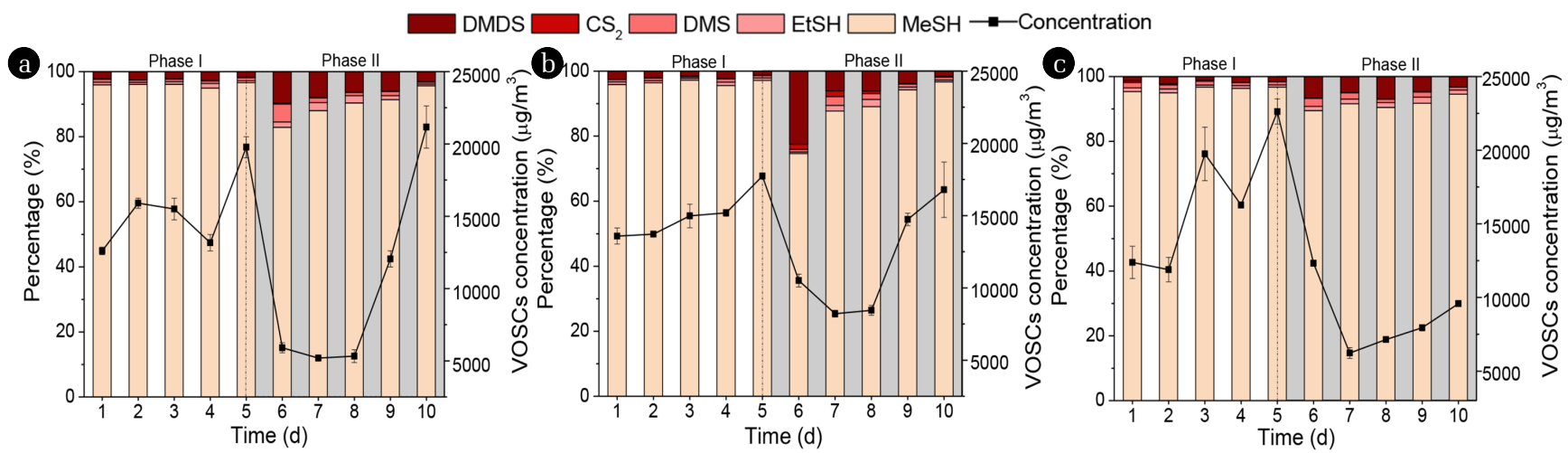

Fig. 4. Variation of the total VOSCs concentration in the headspace and the percentage of VOSCs in Phase I and II with the addition of (a) ferric, (b) hydrogen peroxide, and (c) nitrate.
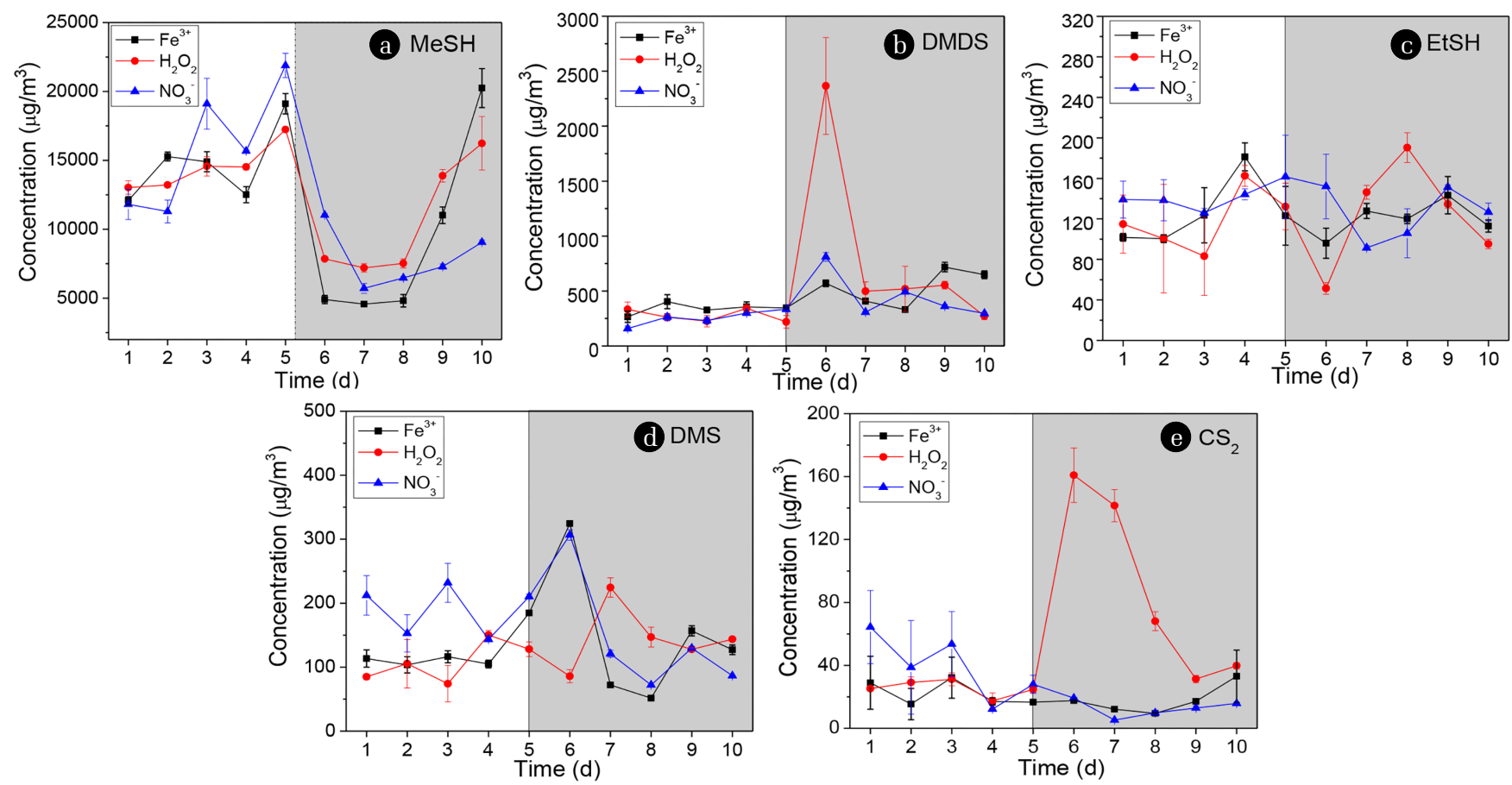

Fig. 5. Concentration variation of each VOSCs in Phase I and II: MeSH (a), DMDS (b), EtSH (c), DMS (d), DMDS (e).

ments since the average concentrations detected $\left(<350 \mu \mathrm{g} / \mathrm{m}^{3}\right)$ were 1-2 orders of magnitudes lower than DMDS and MeSH (Fig. $5(\mathrm{c})-(\mathrm{e}))$.

\subsection{Variation of Theoretical Odor Concentration .in Headspace Gas}

The theoretical odor concentration (ThOC), which was widely used to determine the main odorous substances [14], was used in this study to assess volatile compounds' pollution potential and to identify the main odorous compounds in the sewer system. The sulfur compounds include $\mathrm{H}_{2} \mathrm{~S}, \mathrm{MeSH}, \mathrm{EtSH}, \mathrm{DMS}, \mathrm{CS}_{2}$, and DMDS, which have all been reported as the main constituents of sewer odor. In terms of the ThOC of sulfur compounds, the contribution of 6 sulfur compounds to the total ThOC of sulfur compounds are shown in Fig. 6. The total ThOC ranged from $8.7 \times 10^{4}$ to $1.3 \times 10^{5}$ for R1 (ferric), from $9.3 \times 10^{4}$ to 1.2 $\times 10^{5}$ for R2 (hydrogen peroxide), and from $8.2 \times 10^{4}$ to 1.5 $\times 10^{5}$ for R3 (nitrate) in the Phase I. After intermittent dosing chemicals, the total ThOC reduced to 40,000-60,000 in the first 3 days of Phase II, and then rebounded again for the $\mathrm{Fe}^{3+}$ and $\mathrm{H}_{2} \mathrm{O}_{2}$ addition. On the other hand, The ThOC of MeSH was nearly thirty times higher than that of $\mathrm{H}_{2} \mathrm{~S}$ or EtSH. Even with intermittent chemical dosing, MeSH was still the main sulfur odor constituent emitted from the liquid phase. These results indicate that $\mathrm{MeSH}$ is the main substance causing the significant odor problem in this study, with an average percentage concentration of $93.8 \%$, followed by EtSH (3.4\%) and $\mathrm{H}_{2} \mathrm{~S}(2.8 \%)$. So particular attention needs to be paid to the MeSH which has an extremely low odor threshold $\left(0.15 \mu \mathrm{g} / \mathrm{m}^{3}\right)$. 


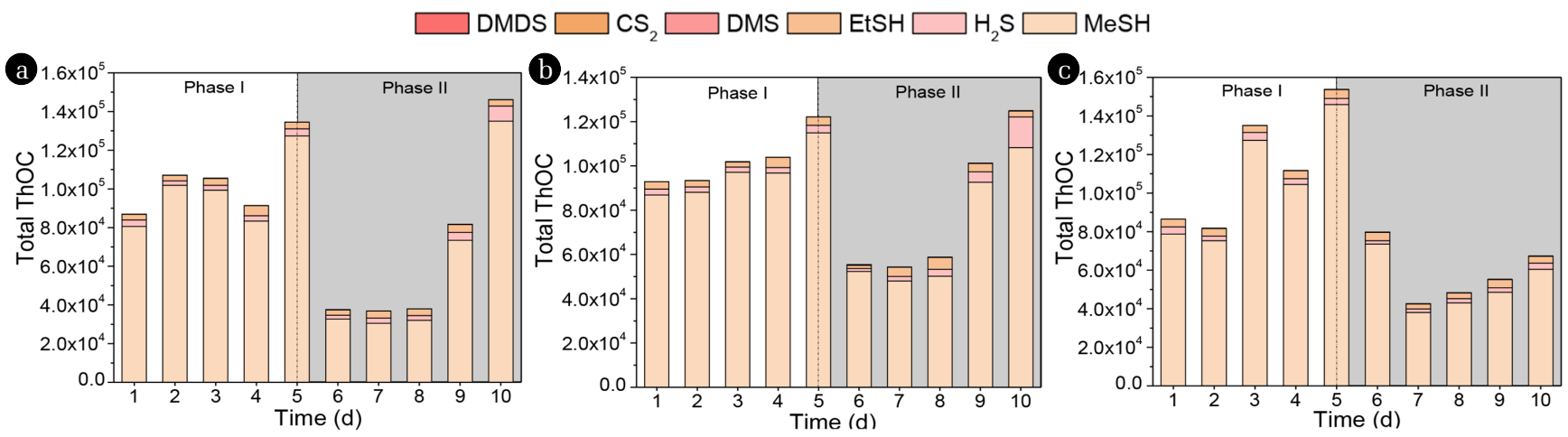

Fig. 6. Variation of total ThOC of 6 VSCs in Phase I and II with the addition of (a) ferric, (b) hydrogen peroxide, and (c) nitrate.

\subsection{Microbial Communities}

Fig. 7 shows the microbial communities before and after intermittent dosing of $\mathrm{Fe}^{3+}, \mathrm{H}_{2} \mathrm{O}_{2}$, and $\mathrm{NO}_{3}^{-}$. The relative abundance of bacterial genera related to sulfate reduction remained around $6.5 \%$ before chemicals addition (Fig. 7(a)), where Desulfovibrio, Sulfurospirillum, Desulfobulbus, and Pseudomonas dominated in the sulfate-reducing bacteria (SRB). No significant relative abundance change in the sulfate-reducing community was observed with all three chemicals intermittent addition, where Desulfovibrio, Sulfurospirillum, Desulfobulbus, and Pseudomonas still dominated in the SRB, which agreed with the results of previous studies that nitrate and ferric addition did not alter the major SRB populations [27, 28]. The addition of $\mathrm{H}_{2} \mathrm{O}_{2}$ also did not affect the SRB activity greatly due to its short lifetime. Therefore, the intermittent dosing of $\mathrm{Fe}^{3+}$,
$\mathrm{H}_{2} \mathrm{O}_{2}$, and $\mathrm{NO}_{3}{ }^{-}$in this study had not altered the relative abundance of SRB. Moreover, the sulfate respiration functional group exhibited a slight increase after chemical intermittent dosing, with a two-fold increase in relative abundance after continuing intermittent dosing (Fig. 8). The sulfate respiration functional group responds to the sulfate reduction, which probably leads to the rebound of VSCs in the later stage of this experiment (Fig. 2 and Fig. 4).

On the other hand, the genera related to sulfide oxidizing bacteria (SOB) comprised approximately $3.6 \%, 3.7 \%$, and $4.6 \%$ of all sequences before $\mathrm{Fe}^{3+}, \mathrm{H}_{2} \mathrm{O}_{2}$, and $\mathrm{KNO}_{3}$ dosing, respectively (Fig. 7(b)). Sulfuricurvum, Novispirillum, Pseudomonas, and Cloacibacterium were the dominant genera among detected 16 genera. SOB sequences increased to around $6 \%$ in relative abundance with $24 \mathrm{~h} \mathrm{H}_{2} \mathrm{O}_{2}$ and nitrate treatment, which may be responsible for the decrease of
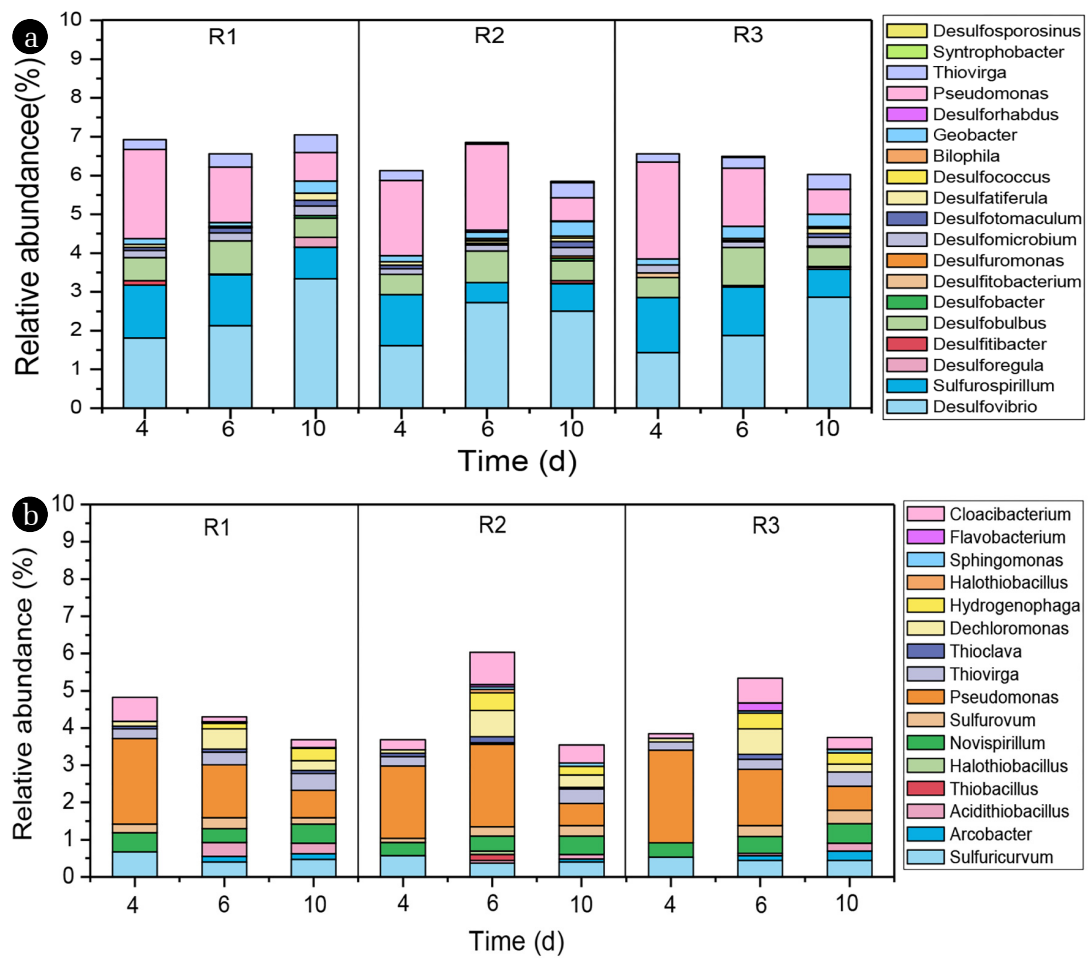

Fig. 7. Microbial communities related to SRB (a) and SOB (b) before and after intermittent chemical dosing on Day 4, Day 6 and Day 10. 


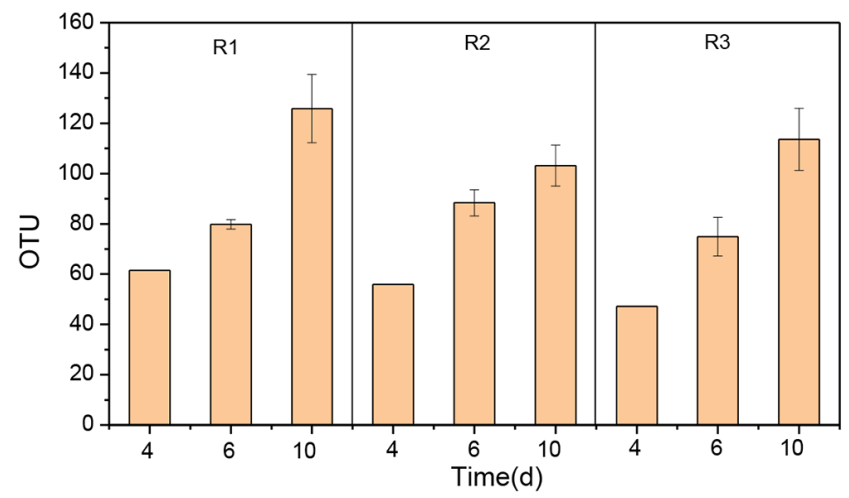

Fig. 8. OTU of the functional group of sulfate respiration.

VSCs in the first days of Phase II. However, the relative abundance of SOB decreased to around $3.5 \%$ in the later Phase II, which could be responsible for the $\mathrm{H}_{2} \mathrm{~S}$ and VOSCs concentration rebound. It is worth noting that the relative abundance of Arcobacter sp. increased after nitrate addition (Fig. 7). Arcobacter sp. are nitrate-reducing, sulfide-oxidizing bacteria (NR-SOB) [29] that effectively compete with other sulfur-oxidizing bacteria by being able to tolerate higher concentrations of $\mathrm{H}_{2} \mathrm{~S}$ and to grow at very low molecular oxygen concentrations [30]. It was demonstrated that NR-SOB has the ability for rapid removal of sulfide even in the absence of molecular oxygen [31]. This indicated that the addition of nitrate may favor the biological oxidation of sulfide by NR-SOB, which is consistent with the literature [32]. After several intermittent dosing, the relative abundance of Arcobacter sp increased from $0.13 \%$ to $0.24 \%$, which was higher than that of others. Besides, the previous study also revealed that syntrophic degradation of VOSCs by methanogens and nitrate-reducing bacteria could exist. The stable VSC compound concentration in the intermittent nitrate dosing strategy was probably attributed to the enrichment of NR-SOB.

The relative abundance of the top 10 abundant families was shown in the Fig. S1. The total relative abundance of bacteria decreased on the day 6 and then increased on the day 10 with the addition of ferric or hydrogen peroxide. However, the total relative abundance continued to decline with the addition of nitrate during the whole phase. Burkholderiaceae was the most abundant family which showed the similar trend. The specific members of the Burkholderiaceae family have been found to contribute to the production of sulfurous volatile compounds in previous studies [33]. Therefore, the relative abundance of Burkholderiaceae decreased continuously when dosing nitrate which could explain the VSCs concentration didn't rebound with addition of nitrate in the late-stage experiment.

However, there are some limitations of this study that should be noted. By using synthetic wastewater in this study, the impact of varying compositions of the wastewater was not evaluated. Real wastewater contains microorganisms, which continuously inoculate the reactor. This will influence the microbial community in the reactor, which cannot be assessed with the use of synthetic wastewater. Besides, the composition of sediment in different reactors may vary considerably which could affect the control effect. Further investigation is recommended in the fieldwork.

\section{Conclusions}

In this study, the VSCs $\left(\mathrm{H}_{2} \mathrm{~S}, \mathrm{MeSH}\right.$, EtSH, DMS, DMDS, and $\left.\mathrm{CS}_{2}\right)$ concentration variation in the sewer headspace gas phase when intermittently dosing ferric iron, hydrogen peroxide, and nitrate were investigated. During intermittent dosing of ferric iron (40 $\mathrm{mg} / \mathrm{L}$ ) and hydrogen peroxide (40 mg/L), the control effect of VSCs in the sewer gas phase was found to be limited. The VSC concentrations increased significantly in the late-stage experiments, even at the end of the experiment around $20 \%$ and $30 \%$, respectively higher than the initial average VSCs concentrations. This result is probably attributed to the element sulfur accumulation and the increase of the sulfur-oxidizing bacteria. However, the intermittent addition of $40 \mathrm{mg} \mathrm{N} / \mathrm{L}$ nitrate has a relatively stable control effect of $\mathrm{H}_{2} \mathrm{~S}$ and VOSCs which maintaining $60 \%$ removal rate, which is probably attributed to the enrichment of nitrate-reducing bacteria that degrade VOSCs. Besides, MeSH was found to be the most abundant compound of the total VOSCs released, accounting for nearly $95 \%$ of the VOSCs before and after chemicals addition. The results of the theoretical odor concentration study indicated that MeSH accounted for around 94\% of the total ThOC, which is the main compound causing the odor problem in this study. More attention should be therefore focused on the MeSH due to its extremely low odor threshold.

\section{Acknowledgment}

The writers gratefully acknowledge financial support from National Key R\&D Program of China (2019YFC0408400).

\section{Author Contributions}

G.Z. (Ph.D student) analyzed data and wrote the manuscript. T.G. (Ph.D student) conducted experiments. Y.C.Z. (Professor) provided research ideas and revised the manuscript. D.Z. (Professor) and Y.P.Z. (Professor) revised the manuscript.

\section{References}

1. Hvitved-Jacobsen T, Vollertsen J, Nielsen A. Aerobic and Anoxic Sewer Processes. Sewer Process; 2013. p.167-214.

2. Zhang L, De Schryver P, De Gusseme B, et al. Chemical and biological technologies for hydrogen sulfide emission control in sewer systems: A review. Water Res. 2008;42:1-12.

3. Jefferson B, Hurst A, Stuetz R, Parsons SA. A comparison of chemical methods for the control of odours in wastewater. Process Saf. Environ. Prot. Trans. Inst. Chem. Eng. Part B. 2002;80:93-99.

4. Liu Y, Dong Q, Shi H. Distribution and population structure characteristics of microorganisms in urban sewage system. Appl. Microbiol. Biotechnol. 2015;99:7723-7734.

5. Jiang G, Gutierrez O, Yuan Z. The strong biocidal effect of free nitrous acid on anaerobic sewer biofilms. Water Res. 
2011;45:3735-3743.

6. Liang S, Zhang L, Jiang F. Indirect sulfur reduction via polysulfide contributes to serious odor problem in a sewer receiving nitrate dosage. Water Res. 2016;100:421-428.

7. Sivret E, Wang B, Parcsi G, Stuetz R. Prioritisation of odorants emitted from sewers using odour activity values. Water Res. 2016;88:308-321.

8. Priyadarsini S, Neelima P. Evaluation of Site Effects Using HVSR Microtremor Measurements in Vishakhapatnam ( India ). Earth Syst. Environ. 2020;4:439-454.

9. Zacharie A, Bessa E, Ngueutchoua G, et al. Heavy metal contamination and its ecological risks in the beach sediments along the Atlantic Ocean ( Limbe coastal fringes, Cameroon ). Earth Syst. Environ. 2020. https://doi.org/10.1007/s41748-020-00167-5.

10. Sharip Z, Balqis S, Razak A, et al. Application of an Effective Microorganism Product as a Cyanobacterial Control and Water Quality Improvement Measure in Putrajaya Lake. Earth Syst. Environ. 2020;4:213-223.

11. Gu T, Tan P, Zhou Y, et al. Characteristics and mechanism of dimethyl trisulfide formation during sulfide control in sewer by adding various oxidants. Sci. Total Environ. 2019;673:719-725.

12. Chen M, Yao X, Ma R, et al. Methanethiol generation potential from anaerobic degradation of municipal solid waste in landfills. Environ. Sci. Pollut. Res. 2017;24:23992-24001.

13. Nagata Y. Measurement of Odor Threshold by Triangle Odor Bag Method. Minist. Environ. - Gov. Japan. 2003;118-127.

14. Guo H, Duan Z, Zhao Y, et al. Characteristics of volatile compound emission and odor pollution from municipal solid waste treating/disposal facilities of a city in Eastern China. Environ. Sci. Pollut. Res. 2017;24:18383-18391.

15. Zhang W, Zhu DZ, Rajaratnam N, et al. Use of Air Circulation Pipes in Deep Dropshafts for Reducing Air Induction into Sanitary Sewers. J. Environ. Eng. 2016;142:04015092.

16. Wang B, Sivret EC, Parcsi G, et al. Reduced sulfur compounds in the atmosphere of sewer networks in Australia: Geographic (and seasonal) variations. Water Sci. Technol. 2014;69:1167-1173.

17. Sheng Y, Chen F, Wang X, Shen G, Fu J. Odorous Volatile Organic Sulfides in Wastewater Treatment Plants in Guangzhou, China. Water Environ. Res. 2008;80:324-330.

18. M. Ksibi. Chemical oxidation with hydrogen peroxide for domestic wastewater treatment. Chem. Eng. J. 2006;119:161-165.

19. USEPA. Hydrogen Sulfide Corrosion In Wastewater Collection And Treatment Systems. Report To Congress. 1991.

20. Kamyshny A, Ekeltchik I, Gun J, et al. Method for the Determination of Inorganic Polysulfide Distribution in Aquatic Systems. Anal. Chem. 2006;78:2631-2639.

21. Zhang L, Keller J, Yuan Z. Inhibition of sulfate-reducing and methanogenic activities of anaerobic sewer biofilms by ferric iron dosing. Water Res. 2009;43:4123-4132.

22. Kim H, McConnell L, Ramirez M, et al. Characterization of odors from limed biosolids treated with nitrate and anthraquinone. J. Environ. Sci. Heal. - Part A Toxic/Hazardous Subst. Environ. Eng. 2005;40:139-149.

23. Lomans BP, Op Den Camp H, Pol A, et al. Role of methanogens and other bacteria in degradation of dimethyl sulfide and methanethiol in anoxic freshwater sediments, Appl. Environ. Microbiol. 1999;65:2116-2121.

24. Lomans BP, Van der Drift C, Pol A, Op den Camp H. Microbial cycling of volatile organic sulfur compounds. Cell. Mol. Life Sci. 2002;59:575-588.

25. Lomans BP, Luderer R, Steenbakkers P, et al. Microbial Populations Involved in Cycling of Dimethyl Sulfide and Methanethiol in Freshwater Sediments. Appl. Environ. Microbiol. 2001;67:1044-1051.

26. He P, Wei S, Shao L, Fan L. Emission potential of volatile sulfur compounds (VSCs) and ammonia from sludge compost with different bio-stability under various oxygen levels. Waste Manag. 2018; 73:113-122.

27. Liu Y, Sharma K, Ni B, et al. Effects of nitrate dosing on sulfidogenic and methanogenic activities in sewer sediment. Water Res. 2015;74:155-165.

28. Cao J, Zhang L, Hong J, Sun J, Jiang J. Different ferric dosing strategies could result in different control mechanisms of sulfide and methane production in sediments of gravity sewers. Water Res. 2019;164:114914.

29. Gevertz D, Telang AJ, Voordouw G, et al. Isolation and characterization of strains CVO and FWKO B, two novel nitrate-reducing, sulfide-oxidizing bacteria isolated from oil field brine. Appl. Environ. Microbiol. 2000;66:2491-2501.

30. Sievert SM, Wieringa EBA, Wirsen CO, et al. Growth and mechanism of filamentous-sulfur formationby Candidatus Arcobacter sulfidicus in opposing oxygen-sulfide gradients. Environ. Microbiol. 2007;9:271-276.

31. De Gusseme B, De Schryver P, De Cooman M, et al. Nitrate-reducing, sulfide-oxidizing bacteria as microbial oxidants for rapid biological sulfide removal. FEMS Microbiol. Ecol. 2009;67:151-161.

32. Haveman SA, Greene EA, Voordouw G. Gene expression analysis of the mechanism of inhibition of Desulfovibrio vulgaris Hildenborough by nitrate-reducing, sulfide-oxidizing bacteria. Environ. Microbiol. 2005;7:1461-1465.

33. Medema MH, Eberl L, Raaijmakers JM, Involvement of Burkholderiaceae and sulfurous volatiles in disease- suppressive soils. ISME J. 2018;12:2307-2321. 